
\title{
OF RATS IN OPEN FIELD TEST AND EXPERIMENTALLY INDUCED SOCIAL STRESS
}

EFFECTS OF NEUROPEPTIDES ON BEHAVIOR

Received 30 June 2020;

Received in revised form 12 August 2020;

Accepted 23 August 2020

\section{Anna Yasenyavskaya ${ }^{1 凶}$ (D), Marina Samotrueva ${ }^{1}$ (D), Aleksandra Tsibizova' ${ }^{1}$ Olga Bashkina ${ }^{1}$ (D), Nikolai Myasoedov² (D), Liudmila Andreeva² (B)}

\author{
${ }^{1}$ Astrakhan State Medical University, Astrakhan; \\ ${ }^{2}$ Kurchatov Institute of Molecular Genetics of National Research Centre, \\ Moscow, Russia
}

\section{yasen_9@mail.ru}

\begin{abstract}
The experiment is devoted to the study of the effect of neuropeptides on the psychoemotional state of rats exposed to experimental social stress. In the process of modeling social stress, inter-male confrontations were observed, as a result of which groups of animals with aggressive and submissive types of behavior were formed. The psychoemotional state of animals which were injected with the registered neuropeptides Semax (Met-Glu-His-PhePro-Gly-Pro) and Selank (Thr-Lys-Pro-Arg-Pro-Gly-Pro), as well as new synthetic compounds of neuropeptide structure - His-Phe-Arg-Trp-Pro-Gly-Pro, Pro-Gly-Pro and Pro-GlyPro-Leu were assessed with the help of open field test based on the results of behavioral responses. It was found that the studied neuropeptides (Semax, Selank, His-Phe-Arg-TrpPro-Gly-Pro, Pro-Gly-Pro and Pro-Gly-Pro-Leu) exhibited a psychomodulatory effect and relieved symptoms of anxietydepressive disorders caused by exposure to social stress.
\end{abstract}

KEY W ORDS - experimental social stress, neuropeptides, Semax, Selank, psychomodulatory effect.

\section{INTRODUCTION}

Despite a significant number of experiments and publications devoted to various aspects of the problem of stress, the assessment of the level of human stress resistance, especially its behavior under exposure to stress is becoming increasingly important and requires detailed study $[1,2]$.

One of the main aspects of considering stress is the fact that stress is a complex of psychological and behavioral responses that reflect a state of inner anxiety or suppression. The behavioral response, being the most flexible and diverse in form, serves as one of the mechanisms for protecting the body from the action of various stress factors. According to a number of researchers its elements are present at all stages of the adaptation process, they are especially pronounced at the stage of disadaptation $[3,4]$.

Currently, researchers pay great attention not only to the study of the factors that cause stress-induced states, but also the way to eliminate them $[5,6,7]$. In this connection a promising option for stressprotective agents has been suggested by a group of neuropeptides, which are endogenous, playing a role in the formation of compensatory-adaptive forces of the body and regulating important homeostatic functions $[8,9,10,11,12,13,14]$. The study of the functions of neuropeptides demonstrates their ability to regulate learning, attention and behavior, and to exhibit neuroprotective, neuroregenerative and other types of activity [15, 16, 17, 18]. Semax (Met-Glu-His-PhePro-Gly-Pro) and Selank (Thr-Lys-Pro-Arg-Pro-GlyPro) are registered representatives of neuropeptides which were developed at the Institute of Molecular Genetics of the Russian Academy of Sciences and used in clinical practice. Along with the already registered drugs new synthetic compounds of neuropeptide structure - His-Phe-Arg-Trp-Pro-Gly-Pro, Pro-Gly-Pro and Pro-Gly-Pro-Leu are of significant interest from the standpoint of the prospects for practical implementation in clinical pharmacology.

The aim of research: to study the effect of neuropeptides on the psychoemotional state of laboratory animals exposed to a model of social stress.

Material and methods. The study was carried out on 130 white male rats. The animals were divided into groups $(\mathrm{n}=10)$ : group 1 - intact animals (control); group 2 - rats exposed to social stress for 20 days and 5 groups of experimental animals exposed to social stress and receiving neuropeptides at doses of $100 \mu \mathrm{g}$ / kg per day intraperitoneally for 20 days: registered drugs Semax (Met-Glu-His-Phe-Pro-Gly-Pro) and Selank (Thr-Lys-Pro-Arg-Pro-Gly-Pro), as well as new compounds His-Phe-Arg-Trp-Pro-Gly-Pro, Pro-GlyPro and Pro-Gly-Pro-Leu.

In our experimental model of social stress rats were paired-housed in cages separated by a transparent partition with holes, which enabled rats to see, hear and smell each other, but at the same time prevented 
physical interaction. The septum was removed for 10 minutes every day, resulting in inter-male confrontation. As a result, groups of animals with aggressive and submissive behaviors were formed.

The psychoemotional state of the animals was assessed by the results of studying behavior in the open field test.

The experiment results were statistically processed using the following programs: Microsoft Office Excel 2007 (Microsoft, USA), BIOSTAT 2008 Professional 5.1.3.1. To process the obtained results, a parametric method was used with the Student $\mathrm{t}$-test with the Bonferroni correction. Statistically significant differences were considered at $\mathrm{p}<0.05$.

\section{RESULTS}

The results of the study of the effect of neuropeptides on the psychoemotional state of laboratory animals under experimental social stress are presented in the table.
Analysis of the obtained data showed that the formation of social stress led to the development of a state of increased anxiety in rats. So in animals with aggressive behavior we registered a decrease of horizontal and vertical motor, specific hole activity by $40 \%\left(\mathrm{p}_{1}<0.01\right)$, $30 \%\left(\mathrm{p}_{1}<0,05\right)$ and $35 \%\left(\mathrm{p}_{1}<0,01\right)$ respectively and transitions through the central zone of the test is 35\% $\left(p_{1}<0,01\right)$ in comparison with the control group of animals. The intensification of short-term grooming and the increase in the number of fecal boluses of almost $1.8\left(\mathrm{p}_{1}<0.05\right)$ and $2\left(\mathrm{p}_{1}<0,01\right)$ times respectively were additionally noted. These changes were also observed in animals with submissive behavior: a decrease in horizontal motor, vertical motor, specific hole activity by almost $50 \%\left(\mathrm{p}_{1}<0.01\right)$ and transitions through the central zone of the test by $45 \%\left(\mathrm{p}_{1}<0.01\right)$ as well as increased grooming and an increase in the number of fecal boluses by $2.5\left(\mathrm{p}_{1}<0.05\right)$ and $1.5\left(\mathrm{p}_{1}<0.01\right)$ times respectively in relation to the control.

Table. The effect of neuropeptides on the emotional state of rats under conditions of social stress

\begin{tabular}{|c|c|c|c|c|c|c|}
\hline \multirow[b]{2}{*}{$\begin{array}{l}\text { Experimental groups of } \\
\text { animals }\end{array}$} & \multicolumn{6}{|c|}{ Behavioral indicators $(M \pm m)$} \\
\hline & 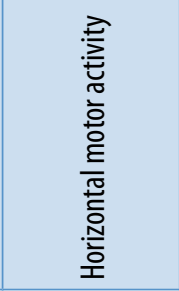 & 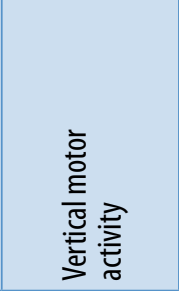 & 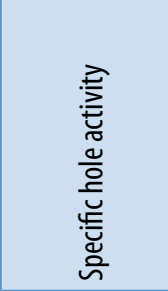 & 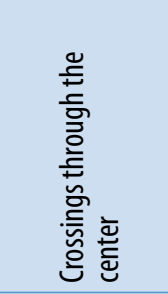 & 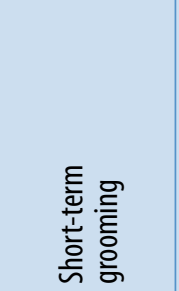 & 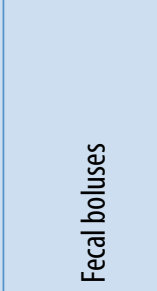 \\
\hline Control & $61,67 \pm 5,8$ & $18,37 \pm 1,6$ & $9,3 \pm 0,8$ & $2,3 \pm 0,2$ & $1,12 \pm 0,1$ & $1,17 \pm 0,2$ \\
\hline \multicolumn{7}{|l|}{ Animals with an aggressive type of behavior } \\
\hline "Social" stress & $37,0 \pm 3,0^{* *}$ & $12,75 \pm 1,16^{*}$ & $6,2 \pm 0,5^{* *}$ & $1,5 \pm 0,1^{* *}$ & $2,0 \pm 0,23^{*}$ & $2,33 \pm 0,25^{* *}$ \\
\hline "Social" stress + Semax & $51,11 \pm 4,14 \#$ & $17,87 \pm 1,52 \#$ & $8,81 \pm 0,64 \# \#$ & $2,1 \pm 0,19 \#$ & $1,21 \pm 0,17 \#$ & $1,33 \pm 0,1 \# \#$ \\
\hline "Social" stress + Selank & $46,83 \pm 3,72 \#$ & $15,29 \pm 1,21$ & $7,67 \pm 0,62$ & $1,67 \pm 0,14$ & $1,33 \pm 0,1 \#$ & $1,57 \pm 0,11 \#$ \\
\hline "Social" stress + His-Phe-Arg-Trp-Pro-Gly-Pro & $47,2 \pm 4,04 \#$ & $16,33 \pm 1,36$ & $8,29 \pm 0,73 \#$ & $2,0 \pm 0,18 \#$ & $1,2 \pm 0,1 \# \#$ & $1,63 \pm 0,14 \#$ \\
\hline "Social" stress + Pro-Gly-Pro & $51,2 \pm 4,73 \#$ & $17,43 \pm 1,81 \#$ & $8,75 \pm 0,62 \# \#$ & $2,4 \pm 0,21 \# \#$ & $1,25 \pm 0,11 \#$ & $1,6 \pm 0,18 \#$ \\
\hline "Social" stress + Pro-Gly-Pro-Leu & $48,57 \pm 4,65 \#$ & $15,33 \pm 1,36$ & $9,25 \pm 0,82 \# \#$ & $2,0 \pm 0,15 \#$ & $1,5 \pm 0,14$ & $1,67 \pm 0,15 \#$ \\
\hline \multicolumn{7}{|l|}{ Animals with a submissive type of behavior } \\
\hline "Social" stress & $33,0 \pm 3,03^{* *}$ & $10,25 \pm 0,82^{* *}$ & $5,67 \pm 0,45^{* *}$ & $1,33 \pm 0,1^{* *}$ & $2,83 \pm 0,37^{* * *}$ & $1,8 \pm 0,15^{* *}$ \\
\hline "Social" stress + Semax & $45,21 \pm 3,88 \#$ & $13,63 \pm 1,0 \#$ & $7,83 \pm 0,58 \#$ & $2,2 \pm 0,17 \# \# \#$ & $1,24 \pm 0,12 \# \# \#$ & $1,18 \pm 0,1 \# \#$ \\
\hline "Social" stress + Selank & $44,2 \pm 4,11 \#$ & $14,0 \pm 1,24 \#$ & $7,25 \pm 0,58 \#$ & $1,5 \pm 0,14$ & $1,67 \pm 0,14 \#$ & $1,5 \pm 0,14$ \\
\hline "Social" stress + His-Phe-Arg-Trp-Pro-Gly-Pro & $43,33 \pm 4,19 \#$ & $13,33 \pm 0,93 \#$ & $8,4 \pm 0,93 \#$ & $1,67 \pm 0,15$ & $1,78 \pm 0,14 \#$ & $1,27 \pm 0,1 \#$ \\
\hline "Social" stress + Pro-Gly-Pro & $49,17 \pm 4,37 \# \#$ & $14,71 \pm 1,21 \# \#$ & $8,5 \pm 0,6 \# \#$ & $2,0 \pm 0,18 \# \#$ & $1,5 \pm 0,11 \# \#$ & $1,17 \pm 0,1 \# \#$ \\
\hline "Social" stress + Pro-Gly-Pro-Leu & $42,75 \pm 3,72 \#$ & $11,83 \pm 0,82$ & $8,25 \pm 1,06 \#$ & $1,5 \pm 0,11$ & $2,0 \pm 0,18 \#$ & $1,44 \pm 0,11$ \\
\hline
\end{tabular}

Note: ${ }^{*}-p<0,05 ;{ }^{* *}-p<0,01 ; * * *-p<0,001$ - comparing with control; \#- $p<0,05 ; \# \#-p<0,01 ; \# \# \#-p<0,001$ — comparing with stress (Student's $t$-test with Bonferroni amendment for multiple comparisons). 
When introducing neuropeptides, results were obtained indicating their ability to eliminate depressive-like disorders in animals developing under induced social stress, both in animals with aggressive and submissive behavior. It was found that in animals with an aggressive type of behavior the administration of Semax and Pro-Gly-Pro contributed to an increase in horizontal motor activity by an average of $40 \%\left(\mathrm{p}_{2}<0.05\right)$, Selank, His-Phe-Arg-Trp-Pro-Gly-Pro and Pro-Gly-Pro-Leu - on average by $30 \%\left(\mathrm{p}_{2}<0.05\right)$ in comparison with the stressed group of animals. The vertical locomotor activity of rats also increased under the influence of neuropeptides: administration of Semax and Pro-Gly-Pro - by an average of $40 \%$ $\left(\mathrm{p}_{2}<0.05\right)$; His-Phe-Arg-Trp-Pro-Gly-Pro - almost $30 \%\left(\mathrm{p}_{2}<0.05\right)$; Selank and Pro-Gly-Pro-Leu - by $20 \%$ however these changes were not statistically significant. It should be noted that in animals with the submissive type, the same tendencies in changes in behavioral parameters were observed: the introduction of Pro-Gly-Pro promoted an increase in horizontal motor activity by almost $50 \%\left(\mathrm{p}_{2}<0.01\right)$, the introduction of other neuropeptides (Semax, Selank, His-Phe-Arg-Trp-Pro-Gly-Pro and Pro-Gly-Pro-Leu) - on average by $35 \%\left(\mathrm{p}_{2}<0.05\right)$ in comparison with the stressed group of animals. The vertical locomotor activity of rats increased under the influence of Semax, Selank and His-Phe-Arg-Trp-Pro-Gly-Pro by an average of $35 \%\left(\mathrm{p}_{2}<0.05\right)$; Pro-Gly-Pro - by almost $45 \%$ $\left(\mathrm{p}_{2}<0.01\right)$; Pro-Gly-Pro-Leu - by $15 \%\left(\mathrm{p}_{2}>0.05\right)$.

The specific hole activity under the stress and the influence of neuropeptides also increased in comparison with the stressed group of animals. It was found that animals with an aggressive type of behavior under the influence of Semax, Pro-Gly-Pro and Pro-Gly-ProLeu showed an increase in this activity by an average of $45 \%\left(\mathrm{p}_{2}<0.01\right)$, His-Phe-Arg-Trp -Pro-Gly-Pro - by more than $30 \%\left(\mathrm{p}_{2}<0.05\right)$, Selank - by more than $20 \%(\mathrm{p} 2>0.05)$, in animals with a submissive type under the influence of Selank, an increase in activity by almost $30 \%\left(\mathrm{p}_{2}<0.05\right)$, under the influence of the rest of the studied neuropeptides by an average of $45 \%$ $\left(\mathrm{p}_{2}<0.05\right)$.

Against the background of the introduction of the studied compounds under stress conditions in animals with an aggressive type of behavior an increase in the number of transitions through the central zone was noted: Semax, His-Phe-Arg-Trp-Pro-Gly-Pro and Pro-Gly-Pro-Leu increased this indicator in on average by $35 \%\left(\mathrm{p}_{2}<0.05\right)$; Pro-Gly-Pro - by $60 \%\left(\mathrm{p}_{2}<0.01\right)$; under the influence of Selank there was a tendency to increase $\left(\mathrm{p}_{2}>0.05\right)$. When studying changes in this indicator in animals with a submissive type of behavior, the same changes were observed but less pronounced.
When assessing the intensity of short-term grooming and the number of fecal boluses under conditions of administration of neuropeptides against the background of social stress in animals with both aggressive and submissive types of behavior, there were changes in the direction of a decrease in these indicators relative to the stressed group by an average of $40 \%$ and $30 \%$, respectively.

\section{CONCLUSION}

Thus, the results obtained confirm the ability of the studied neuropeptides (Semax, Selank, His-PheArg-Trp-Pro-Gly-Pro, Pro-Gly-Pro and Pro-Gly-ProLeu) to exhibit a psychomodulatory effect correcting symptoms of anxiety and depression arising under induced social stress.

\section{AC KNOWLEDGMENTS}

The reported study was funded by Russian Foundation for Basic Research (RFBR) according to the research project № 19-04-00461.

\section{REFERENCES}

1. Bartolomucci A., Leopardi R. Stress and Depression: Preclinical Research and Clinical Implications. PLoS ONE. 2009; 4(1): 4265. https://doi. org/10.1371/journal.pone.0004265

2. Tarasov VV, Kudryashov NV, Chubarev VN, Kalinina TS, Barreto GE, Ashraf GM, Aliev G. Pharmacological Aspects of Neuro-Immune Interactions. Current Pharmaceutical Design. 2018; 24 (1): 15-21. doi: 10.2174/1381612823666170829135115.

3. Baune B. Conceptual Challenges of a Tentative Model of Stress-Induced Depression. PLoS ONE. 2009; 4(1): 4266. https://doi.org/10.1371/journal. pone. 0004266

4. Miguel Z. De, Vegas O., Garmendia L. De Behavioral coping strategies in response to social stress are associated with distinct neuroendocrine, monoaminergic and immune response profiles in mice. Behavioural Brain Research. 2011; 8: 12. doi: 10.1016/j. bbr.2011.08.011

5. Borbély E, SCheich B, Helyes Z. Neuropeptides in learning and memory. Neuropeptides. 2013; 47(6): 439-50. doi: 10.1016/j.npep.2013.10.012.

6. Hökfelt T, Broberger C, Xu ZQ, Sergeyev V, Ubink R, DieZ M. Neuropeptides - an overview. Neuropharmacology. 2000; 39(8):1337-56. doi: $10.1016 / \mathrm{s} 0028-3908(00) 00010-1$.

7. ThIELE TE. Neuropeptides and Addiction: An Introduction. International Review of Neurobiology. 2017; 136: 1-3. doi: 10.1016/bs.irn.2017.07.001.

8. Fricker LD. Carboxypeptidase $E$ and the Identification of Novel Neuropeptides as Potential Therapeutic Targets. Advances in pharmacology. 2018; 82: 85-102. doi: 10.1016/bs.apha.2017.09.001 
9. Gonzalez-Rey E, Delgado-Maroto V, Souza Moreira L, Delgado M. Neuropeptides as therapeutic approach to autoimmune diseases. Current Pharmaceutical Design. 2010; 16(28): 3158-72. doi: $10.2174 / 138161210793292465$.

10. KanUNNikova NP. Neuroprotective properties of neuropeptides. Journal of the Grodno State Medical University. 2017; 15(5): 492-498. doi: 10.25298/22218785-2017-15-5-492-498

11. Kovac $S$, Walker MC. Neuropeptides in epilepsy. Neuropeptides. 2013; 47(6): 467-75. doi: 10.1016/j. npep.2013.10.015.

12. Slominsky PA, Shadrina MI, Kolomin TA, Stavrovskaya AV, Filatova EV, Andreeva LA, ILlarioshinin SN, Myasoedov NF. Peptides semax and selank affect the behavior of rats with 6-OHDA induced PD-like parkinsonism. Doklady Biological Sciences. 2017; 474 (1): 106-109. doi: 10.1134/ S0012496617030048. (in Russ.)

13. Souza-Moreira L, Campos-Salinas J, Caro M, Gonzalez-Rey E. Neuropeptides as pleiotropic modulators of the immune response. Neuroendocrinology. 2011; 94 (2): 89-100. doi: $10.1159 / 000328636$.

14. Tajti J, Szok D, Majláth Z, Tuka B, Csáti A, VÉCSEI L. Migraine and neuropeptides. Neuropeptides. 2015; 52: 19-30. doi: 10.1016/j. npep.2015.03.006.
15. Yasenyavskaya A.L., Samotrueva M.A. Bashinina O.A., Andreeva L.A., Myasoedov N.F., Tyurenkov I.N., Karaulov A.V. Neuropeptide regulation of immunity. Immunology. 2018; 39 (5-6): 326-336. DOI: http://dx.doi. org/10.18821/0206-4952-2018-39-5-6-326-336 (in Russ.)

16. Lebedeva IS, Panikratova YR, Sokolov OY, KupRIYANOV DA, RuMSHISKAYA AD, KosT NV, Myasoedov NF. Effects of Semax on the Default Mode Network of the Brain. Bulletin of Experimental Biology and Medicine. 2018; 165 (5): 653-656. doi: 10.1007/s10517-018-4234-3. (in Russ.)

17. Medvedeva EV, Dmitrieva VG, Limborska SA, Myasoedov NF, Dergunova LV. Semax, an analog of $\operatorname{ACTH}((4-7))$, regulates expression of immune response genes during ischemic brain injury in rats. Molecular Genetics and Genomics. 2017; 292 (3): 635-653. doi: 10.1007/s00438-017-1297-1. (in Russ.)

18. Samotrueva M.A., Yasenyavskaya A.L., MurTAlieva V.K., Bashinina O.A., MYasoedov N.F., Andreeva L.A., Karaulov A.V. Experimental substantiation of application of semax as a modulator of immune reaction on the model of "social" stress. Bulletin of Experimental Biology and Medicine. 2019; 166 (6): 754-758. (in Russ.) 